\title{
Granzyme B is expressed in mouse mast cells in vivo and in vitro and causes delayed cell death independent of perforin
}

\begin{abstract}
J Pardo ${ }^{1,7}$, R Wallich ${ }^{2,7}$, K Ebnet $^{3}$, S Iden ${ }^{3}$, H Zentgraf ${ }^{4}$, P Martin ${ }^{1}$, A Ekiciler ${ }^{1}$, A Prins ${ }^{5}$, A Müllbacher ${ }^{5}$, M Huber ${ }^{6}$ and MM Simon ${ }^{\star, 1}$
Mast cells respond to pathogens and allergens by secreting a vast array of preformed and newly synthesized mediators, including enzymes, vasoactive amines, lipid mediators, cytokines and chemokines, thereby affecting innate and adaptive immune responses and pathogenesis. Here, we present evidence that skin-, but not lung-associated primary mast cells as well as in vitro-differentiated bone marrow-derived mast cells (BMMC) express granzyme (gzm) B, but not gzmA or perforin (perf). GzmB is associated with cytoplasmic granules of BMMC and secreted after Fc $\varepsilon$-receptor-mediated activation. BMMC from wild type but not gzmB-deficient mice cause cell death in susceptible adherent target cells, indicating that the perf-independent cytotoxicity of BMMC is executed by gzmB. Furthermore, gzmB induces a disorganization of endothelial cell-cell contacts. The data suggest that activated mast cells contribute, via secreted $\mathrm{gzmB}$, to cell death, increased vascular permeability, leukocyte extravasation and subsequent inflammatory processes in affected tissues.
\end{abstract}

Cell Death and Differentiation (2007) 14, 1768-1779; doi:10.1038/sj.cdd.4402183; published online 29 June 2007

Mast cells are mainly known for their role in allergic disorders, but have recently been shown to exert many other immune functions. ${ }^{1}$ Mast cells constitute a heterogeneous population residing in mucosal and connective tissues and are found in close association with endothelial cells (ECs) of blood vessels and nerves. Mast cell subsets are functionally distinct and their profile of expressed mediators is altered in disease states. ${ }^{1-3}$

On receiving the appropriate stimuli, mast cells can release three classes of mediators: preformed granule-associated mediators, such as histamine, tryptase, chymase and other proteases; newly generated lipid mediators, that is, leukotrienes and prostaglandins; and a variety of cytokines and chemokines. ${ }^{1-3}$ In contrast to lipid mediators and cytokines, which have to be synthesized de novo, preformed granuleassociated mediators can be secreted almost without delay after triggering of certain receptors. ${ }^{1}$

Recent work on mouse has identified transcripts for the serine proteinase granzyme (gzm) B in cultured naive mast cells. ${ }^{4}$ However, protein expression of gzmB has not been shown. GzmB together with gzmA and perforin (perf) are key components of the lytic machinery of cytotoxic leukocytes, that is, natural killer (NK) cells and cytotoxic $\mathrm{T}$ lymphocytes $(\mathrm{CTL})^{5}$ and are released into the immunological synapse formed between NK/CTL and their target cells. ${ }^{6}$ After localization of the gzms to the cytosol and/or nucleus of target cells, gzmA and gzmB initiate alternative proteolytic pathways leading to apoptosis. These processes are strictly dependent on perf., ${ }^{5,7}$ However, evidence of extracellular function(s) of $\mathrm{gzmA}^{8,9}$ and $\mathrm{gzmB},{ }^{10,11}$ independent of perf exists. These extracellular activities of gzms are implicated in inflammation and processes of leukocyte extravasation. ${ }^{10,12,13}$ Both, gzmA and/or gzmB cleave extracellular proteins such as fibronectin, collagen IV, vitronectin and/or laminin. ${ }^{8,10,11} \mathrm{GzmB}$ also degrades the cartilage proteoglycan aggrecan, ${ }^{14}$ induces perf-independent cell detachment and delayed cell death (anoikis) in adherent smooth muscle cells $(\mathrm{SMCs})^{11}$ and in EC. ${ }^{10}$ This occurs by remodeling of the extracellular matrix. ${ }^{10}$

Here, we report on the expression of gzmB in skinassociated and in in vitro-differentiated mouse mast cells and provide evidence that mast cell-derived gzmB induces cell detachment and cell death of adherent target cells.

\section{Results}

Skin- but not lung-associated mouse mast cells express gzmB in vivo. Histochemical analysis of skin and lung tissues from naive mice showed that skin-associated mast

\footnotetext{
${ }^{1}$ Metschnikoff Laboratory, Max-Planck-Institut for Immunbiology, Freiburg, Germany; ${ }^{2}$ Institute for Immunology, University Clinic Heidelberg, Heidelberg, Germany; ${ }^{3}$ Institute for Medical Biochemistry, ZMBE, University of Muenster, Muenster, Germany; ${ }^{4}$ German Cancer Research Center, Heidelberg, Germany; ${ }^{5}$ John Curtin School of Medical Research, Australian National University, Canberra, Australia and ${ }^{6}$ Molecular Immunology, Biology III, University of Freiburg \& Max-Planck-Institut for Immunbiology, Freiburg, Germany

${ }^{*}$ Corresponding author: MM Simon, Metschnikoff Laboratory, Max-Planck-Institut für Immunbiologie, Stübeweg 51, Freiburg, Germany.

Tel: + 49-761-5108-533; Fax: + 49-761-5108-529, E-mail: simon@ immunbio.mpg.de

${ }^{7}$ These authors contributed equally to this work.

Keywords: mast cells; anoikis; granzyme B

Abbreviations: B6, C57BL/6 mouse strain; BMMC, bone marrow-derived mast cell; CTL, cytotoxic T lymphocytes; EC, endothelial cell; gzm, granzyme; FHL, familial hemophagocytic lymphohistiocytosis; NK, natural killer cell; perf, perforin; RA, rheumatoid arthritis; rgzm, recombinant granzyme; SLO, streptolysin; SMC, smooth muscle cells

Received 08.11.06; revised 15.5.07; accepted 16.5.07; Edited by SJ Martin; published online 29.6.07
} 
cells stained with both, safranin and alcian blue, whereas mast cells from lung tissue only stained with alcian blue, supporting previously published work. ${ }^{15}$ Mast cells were localized between SMCs and around small vessels in the skin (Figure 1a and b) and in subepithelial tissue layers of bronchi and bronchioles of the lung (Figure 1c). As seen in Figure $1 \mathrm{a}$ and $\mathrm{b}$, only skin- but not lung-associated mast cells expressed gzmB, which was mainly associated with cytoplasmic granules. Tissue sections of both tissues stained with either $\alpha$ gzmA IgG or normal rabbit IgG were similar to untreated controls (data not shown).

In vitro-differentiated bone marrow-derived mast cells express gzmB but not gzmA or perf. Mast cells differentiated in vitro from bone marrow of C57BL/6 mouse strain (B6), ${ }^{16}$ termed bone marrow-derived mast cells (BMMC), consisted of greater than $95 \% \mathrm{CD} 117^{+} \mathrm{ST} 2^{+}$ cells with only a minority (between 0.6 to $1 \%$ ), if any, also staining for Gr-1 (data not shown), Mac-1, NK1.1, B220, CD4 or CD8 (Figure 2a). Further analysis by EM verified that the majority of $\mathrm{CD}_{117^{+}} \mathrm{ST}^{+}$cells are of mast cell origin (Figure 2b). When BMMC of $\mathrm{B} 6$ and $\mathrm{gzmB}^{-1-}$ mice were analyzed by FACS for intracellular expression of gzmA and gzmB proteins, all B6 BMMC $\left(96 \% \mathrm{CD} 117^{+} \mathrm{ST}^{+}\right.$; Figure 3a, upper panel) specifically stained intracellularly with $\alpha$ mgzmB- but not $\alpha \mathrm{mgzmA}$-specific immune serum (IS), whereas gzmB ${ }^{-1-}$ BMMC gave no signal with either of the two IS (Figure 3a, lower panel).

The specificity of both IS for the respective gzm was confirmed, as before, ${ }^{17}$ by showing that the CTL line 1.3E6, but not the thymoma line, EL4, intracellularly stained for both gzms (Figure $3 b$, left panel) and that specific bands of the expected size of $\mathrm{MW} \sim 30 \mathrm{kDa}$ for gzmB were found in Western blot (WB) with cell lysates from 1.3E6 and ex vivoderived LCMV-immune $\mathrm{B} 6$ and $\mathrm{gzmA}^{-1-}$, but not $\mathrm{gzmB}^{-/-}$ CTL, and not in EL4 cells (Figure 3b, right panel). RT-PCR analysis showed that $\mathrm{B} 6$ and $\mathrm{gzmB}^{-1-}$ BMMCs expressed transcripts specific for $M c$-cpa with similar intensity, but only B6 BMMC contained, in addition, gzmB-specific mRNA (Figure $3 c$, left panel). Furthermore, none of the two BMMC

a
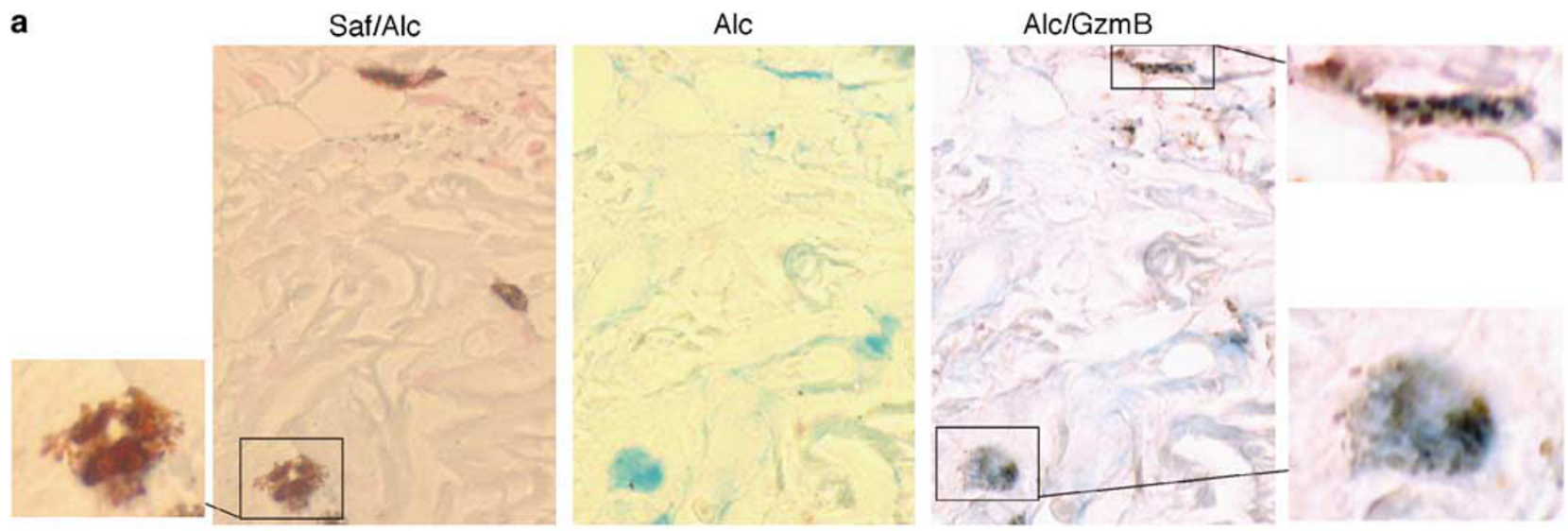

b
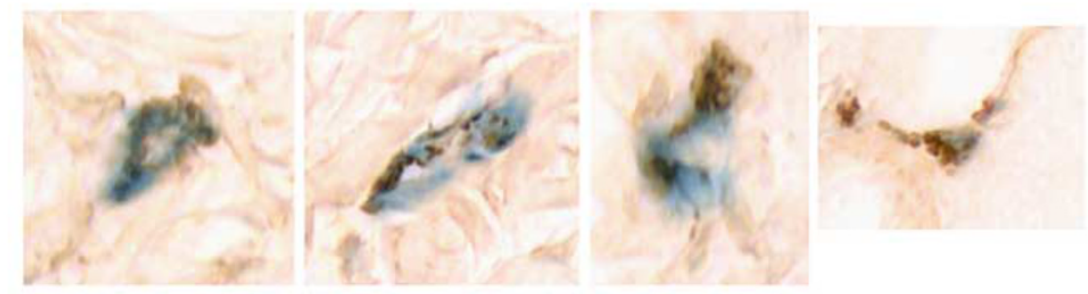

C
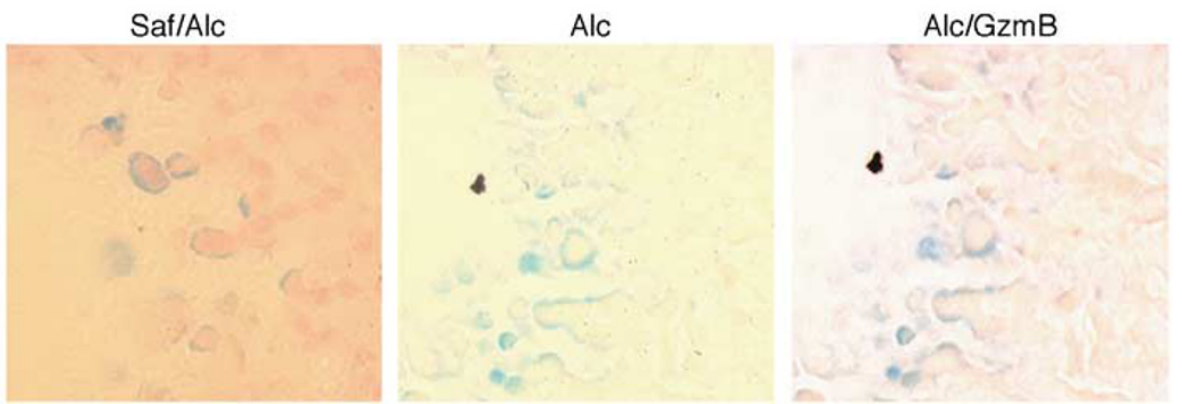

Figure 1 Mouse skin- but not lung-associated mast cells express gzmB. Tissue sections of skin and lung from naive B6 mice were stained with safranin/alcian blue (saf/alc) (a, c) or alcian blue alone (alc) (a, c), as described in Materials and methods. Consecutive sections of alcian blue-stained tissue were stained for gzmB (a, b, $\mathbf{c})$ as described in Materials and methods. (a, c) Pictures of the sequential sections (saf/alc versus alc). (a) Magnifications from the respective location on the same section (alc/gzmB) are shown. (b) Different skin-associated mast cells staining for alcian blue and gzmB are shown. Original magnification: $\times 1000$ 

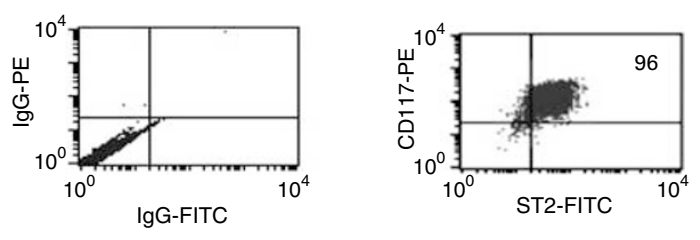

n.d.
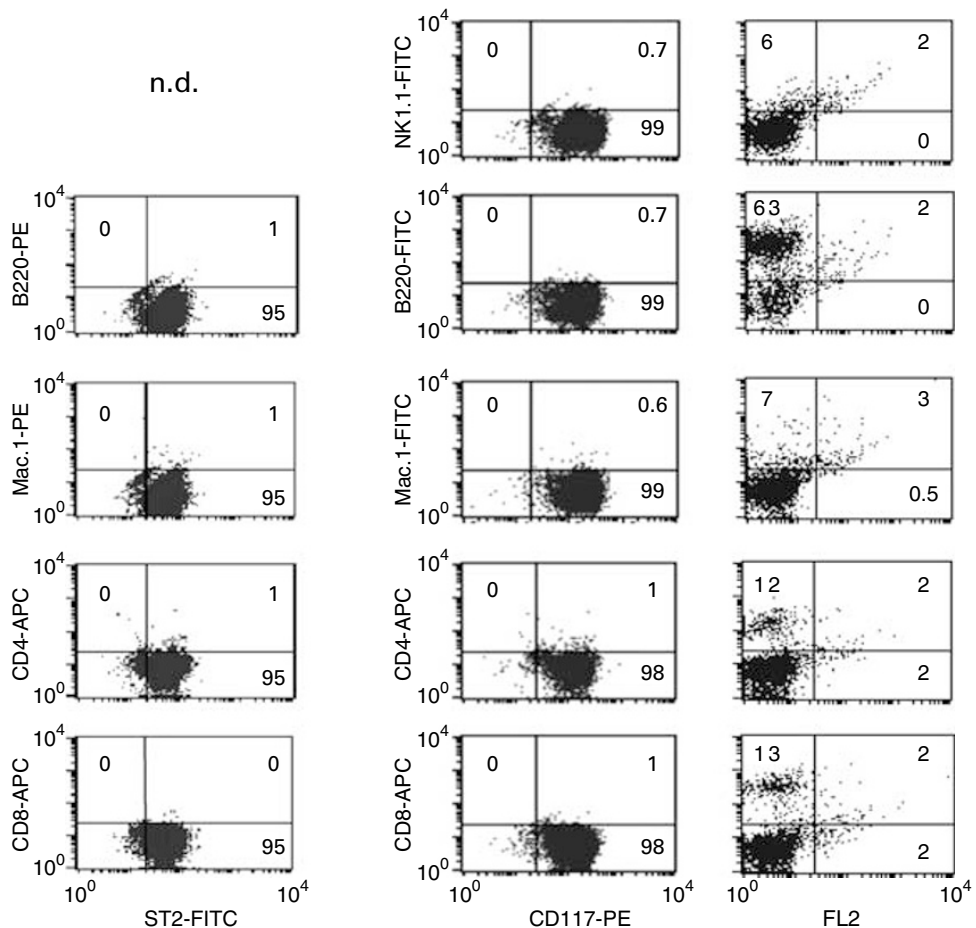

b
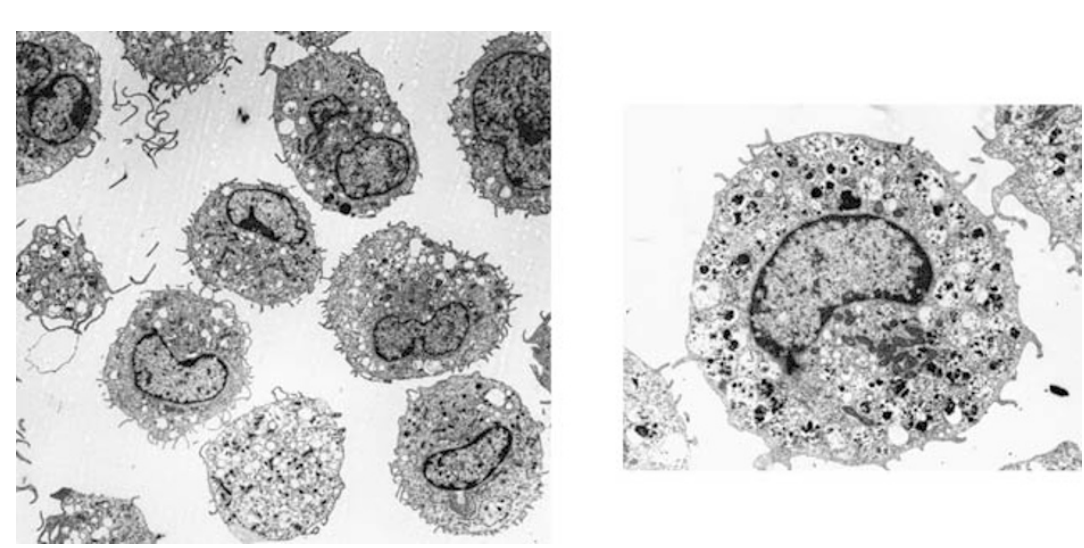

Figure 2 Phenotypic and EM analysis of mouse BMMC (a) BMMC from B6 mice were generated and analyzed for the surface markers c-kit (CD117), ST2, B220, Mac-1, NK1.1, CD8 or CD4 by FACS, as described in Materials and methods. Normal IgG (IgG-PE/IgG-FITC) was included as negative control. Numbers represent the percentage of cells in each quadrant. As positive control for the markers B220, Mac-1, NK1.1, CD8 or CD4, normal splenocytes were stained with the respective Ab. (b) Survey electron micrograph of a typical B6 BMMC population; magnification $\times 1850$ (top). A representative cell from the B6 BMMC population showing numerous vacuoles mostly filled with electron dense material; original magnification $\times 4000$ (bottom)

populations expressed gzmA-, Prf-1 (Figure 3c, left panel) or any of the other gzm-specific mRNAs, including $g z m C, D, E$, $F, G, K$ and $M$ (data not shown). ${ }^{5} 1.3 \mathrm{E} 6$ and EL4 were negative for Mc-cpa mRNA and showed the expected expression patterns for gzmA, gzmB and Prf1 transcripts
(Figure 3c, left panel). ${ }^{17}$ In addition, only B6, but not gzmB ${ }^{-/-}$ BMMC produced gzmB, and neither of them gzmA or perf (Figure 3c, right panel). The control cells, 1.3E6 and EL4, showed the expected banding patterns for gzms and perf proteins in WB. Confocal microscopy revealed a granular-like 
a
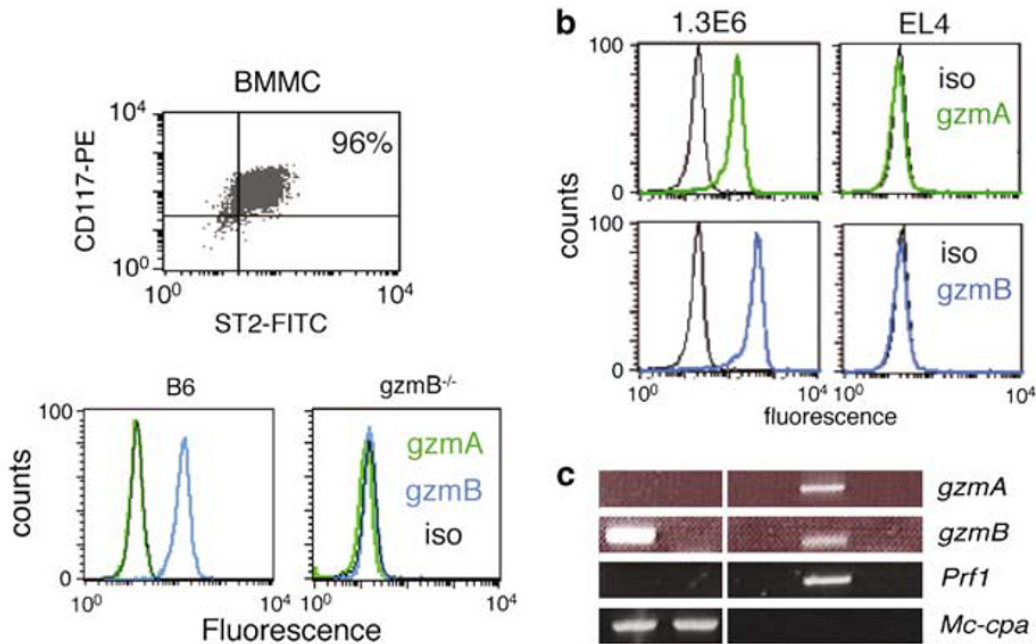

C

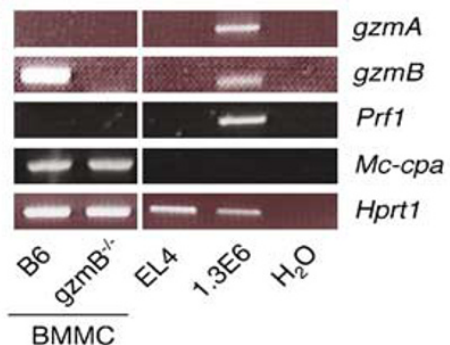

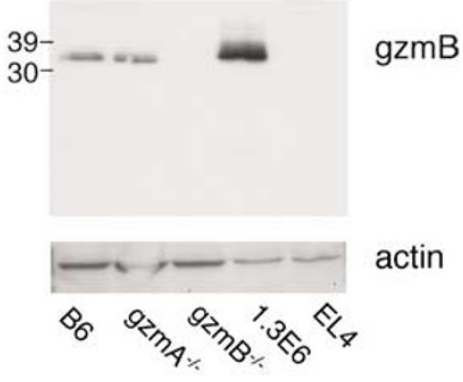

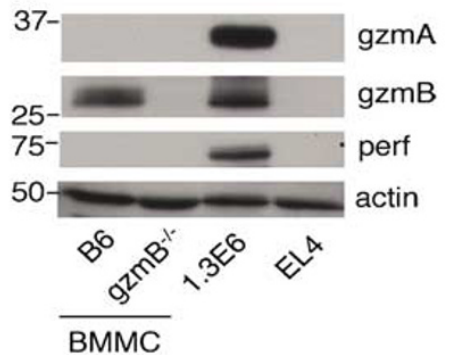

d
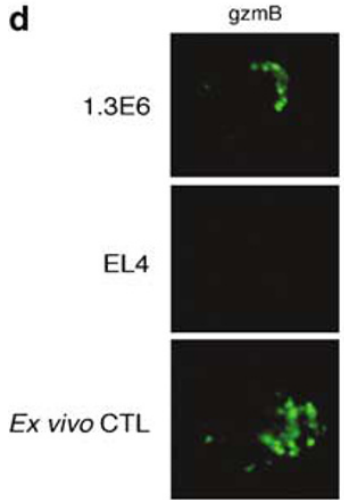

BMMC

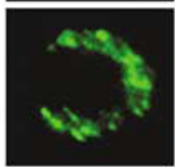

BMMC

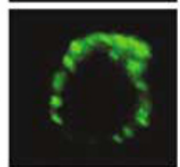

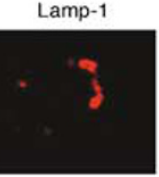
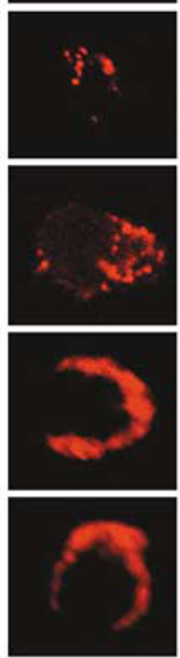
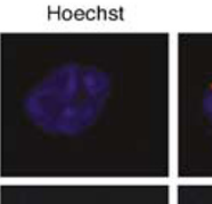

merge
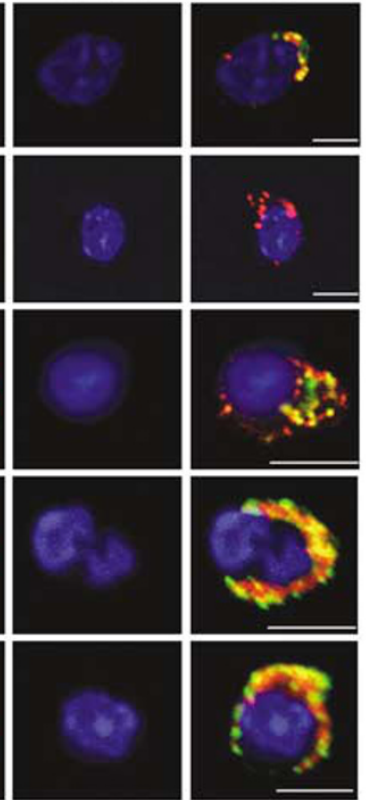

e

BMMC lysates

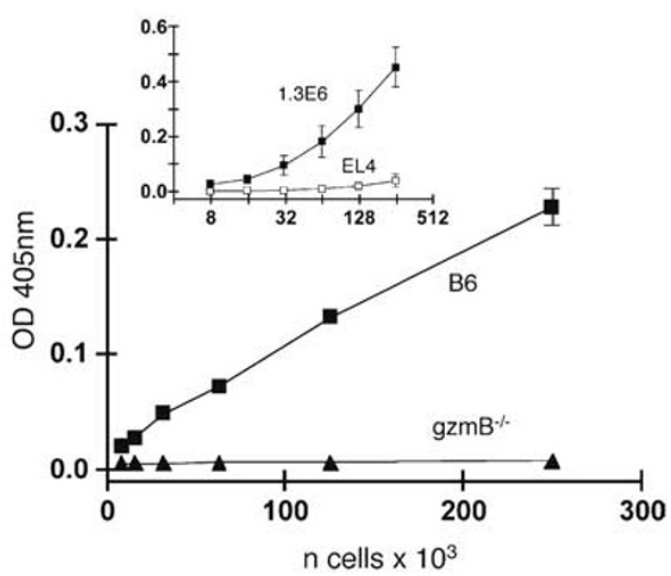

Figure 3 BMMC express gzmB, but not gzmA and perf in cytoplasmic granules. (a) BMMC from B6 and gzmB ${ }^{-1-}$ mice were generated and analyzed for intracellular gzmA and gzmB expression by FACS, using amgzmA or $\alpha \mathrm{mgzmB}$ IS, as described in Materials and methods. As controls, the T cell lines 1.3E6 (CTL, expressing both gzmA and gzmB) and EL4 (thymoma, negative control) were used (b, left panel). The specificity of the $\alpha \mathrm{mgzmA}$ and $\alpha \mathrm{mgzmB}$ IS was verified by WB, using cell extracts from 1.3E6, EL4 or from ex vivo-derived LCMV-immune CTL from B6, $\mathrm{gzmA}^{-1--}$ or gzmB ${ }^{-1-}$ mice (b, right panel) as indicated. (c) RT-PCR (left panel) and WB (right panel) analyses were performed with mRNA or cell lysates, respectively, from 1.3E6, EL4 and B6 and gzmB ${ }^{-1-}$ BMMC, using specific primer pairs for Prf1, gzmA, gzmB or Mc-cpa as well as the amgzmA and $\alpha \mathrm{mgzmB}$ IS and the $\alpha$ perf mAb, as described in Materials and methods. As controls, Hprt1 was used for RT-PCR and actin for WB. (d) Confocal images showing B6 BMMC, 1.3E6, ex vivo-derived LCMV-immune CTL and EL4 stained with amgzmB IS (green) and Lamp-1 (red). Cells were mounted in a drop of Fluoromount G containing $10 \mu \mathrm{g} / \mathrm{ml}$ Hoechst 33342 and fluorescence images were taken at room temperature on a confocal microscope (TCS SP2; Leica) using a $\times 40$ objective (HCX PL APO CS; Leica), NA 1.25, immersion oil and confocal software (version 2.61; all Leica). Photoshop CS2 software (Adobe) was used for minor adjustments to contrast. Bars $6 \mu$ m. Data shown are representative of at least three independent experiments. (e) Cell lysates of $\mathrm{B} 6$ and gzmB ${ }^{-1}$ BMMC were tested for gzmB activity on the respective chromogenic substrate; cell lysates of $1.3 \mathrm{E} 6$ or EL4 served as controls (inset). Data are given as mean \pm S.E.M. of three independent experiments

staining pattern of B6 BMMC, with gzmB and LAMP-1, a prominent lysosomal membrane marker ${ }^{18}$ colocalizing to great extent in these lysosomal compartments (Figure 3d). This suggests that in BMMC, gzmB mainly accumulates in cytosolic granules, similar to 1.3E6 CTL and ex vivo-derived LCMV-immune CTL, where the majority of LAMP-1-positive organelles also expressed gzmB (Figure $3 \mathrm{~d}$ ). ${ }^{19}$ The finding that $\mathrm{B} 6$, but not $\mathrm{gzmB}^{-/-}$, mast cell lysates were able to cleave 
a gzmB-specific chromogenic substrate (Figure 3e) indicates that in lysates from mouse BMMC, gzmB is enzymatically active.

Mouse BMMC secrete gzmB upon antigen-mediated crosslinking of the Fc\&R1. Next, it was tested whether gzmB is secreted by BMMC upon Fc\&R1-mediated degranulation, including the granule marker, $\beta$-hexosaminidase. $^{20} \mathrm{~B} 6$ or $\mathrm{gzmB}^{-1-}$ BMMC were loaded with DNP-
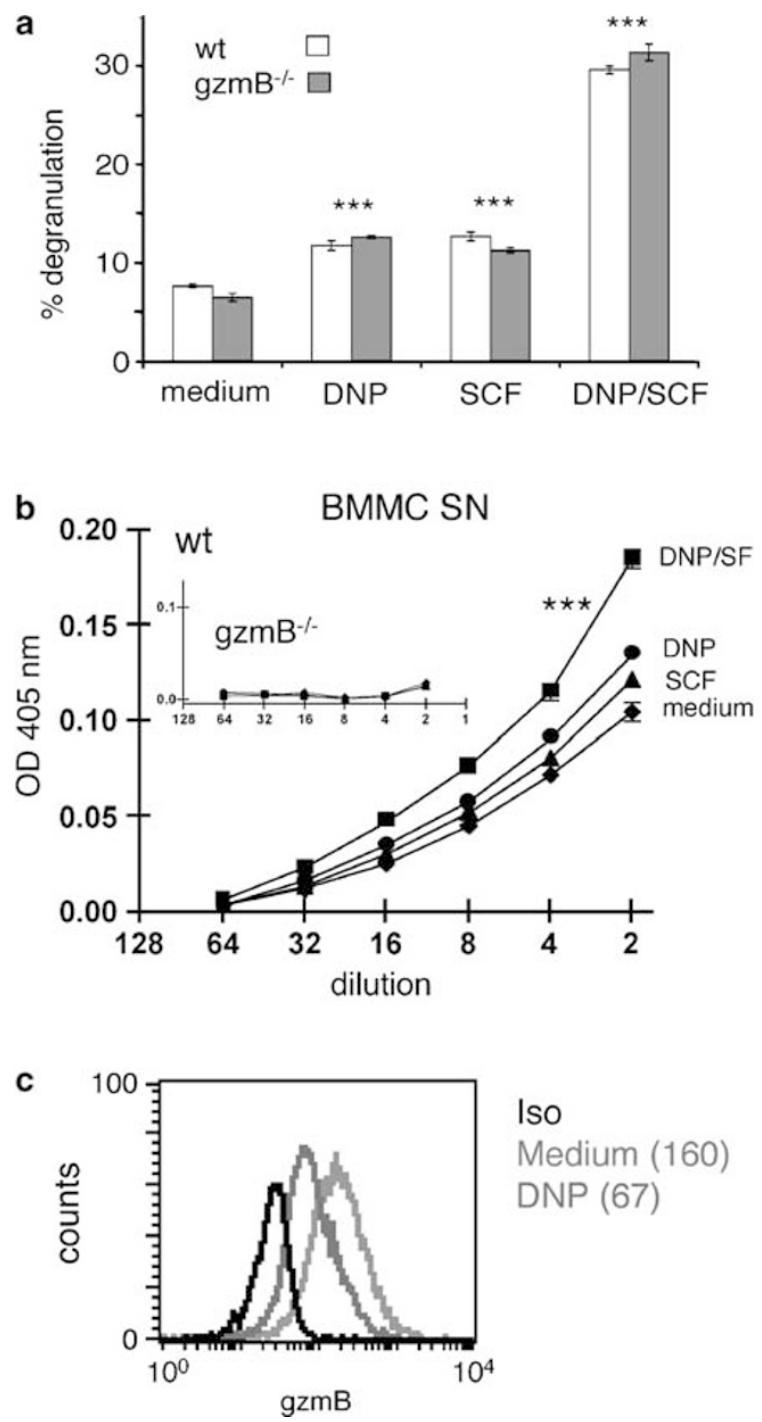

Figure 4 BMMC-associated gzmB is enzymatically active and secreted upon FceR1-mediated activation (a, b) B6 and gzmB ${ }^{-1}$ BMMC were preloaded with DNP-specific IgE $A b$ and subsequently challenged with either DNP-HSA (DNP), SCF or a mixture thereof for 30 min. Mock-treated (medium) B6 BMMC served as controls. BMMC SNs were tested for $\beta$-hexosaminidase (a) or gzmB activity (b). Data are given as mean \pm S.E.M. of two independent experiments. (a) ${ }^{* * *}$ Significantly different analyzed by 2 way ANOVA with Bonferri posttest by comparing every experimental with control groups. (b) ${ }^{* \star}$ Significantly different $(P<0,001)$ comparing every treatment with medium. (c) Mock-treated or -challenged (DNP-HSA; $30 \mathrm{~min}$ ) IgE-preloaded B6 BMMC were analyzed for intracellular gzmB by FACS (numbers in parenthesis indicate the mean intensity of gzmB-related fluorescence). A representative experiment of three independent experiments is shown reactive $\lg$ E and stimulated with either DNP-HSA, SCF or both for $30 \mathrm{~min}$. Similar high levels of $\beta$-hexosaminidase, substantially exceeding those of controls (no stimulus), were secreted from both $\mathrm{B} 6$ or $\mathrm{gzmB}^{-1-} \mathrm{BMMC}$, when challenged with both DNP-HSA and SCF (Figure 4a). As expected, ${ }^{21}$ less $\beta$-hexosaminidase was released from both BMMC populations in response to either SCF or DNP alone (Figure 4a). When challenged under similar conditions, only B6, but not gzmB ${ }^{-1-}$ BMMC secreted enzymatically active gzmB (Figure $4 \mathrm{~b}$ ). The amount of secreted gzmB was highest in B6 BMMC incubated with a mixture of DNP-HSA and SCF, intermediate with DNP-HSA and lowest with SCF. Furthermore, FACS analysis showed that gzmB-related mean fluorescence was considerably reduced in DNP-HSAstimulated (67), as compared to mock-treated (160) BMMC (Figure 4c).

GzmB-induced detachment of adherent mouse embryonic fibroblasts leads to anoikis. To examine possible extracellular function(s) of BMMC-derived gzmB on adherent bystander cells and to establish optimal conditions, B6 mouse embryonic fibroblasts (MEFs) were first exposed to increasing amounts of active recombinant mouse gzmB (rgzmB). A dose-dependent change of B6 MEF morphology (rounding up) was observed after $4 \mathrm{~h}$ (Figure 5a; gzmB, streptolysin (SLO)), which was accompanied by a loss of cell adherence. However, even at $20 \mu \mathrm{g} / \mathrm{ml} \mathrm{rgzmB}$, apoptotic morphology and/or cell death of MEFs (regrowth) were rarely seen (Figure 5b, upper panel). Inactive recombinant gzmB (pro-gzmB) had no effect on adherence (4 h; Figure $5 \mathrm{a}$ ) or viability (Figure $5 \mathrm{~b}$ ) of MEFs.

When MEFs were exposed to increasing amounts of rgzmB in the presence of sublytic doses of SLO $(4 \mathrm{~h})$, the dosedependent detachment (not detectable below $2 \mu \mathrm{g} / \mathrm{ml} \mathrm{rgzmB}$, data not shown) and rounding up of MEFs was much faster and more pronounced compared to MEFs treated solely with rgzmB and associated with typical apoptotic morphology (Figure 5a). The marked induction of cell death ( $50 \%$, compared to untreated control) was further verified by comparing regrowth of rgzmB $(20 \mu \mathrm{g} / \mathrm{ml})$ plus SLO-treated versus control MEFs (Figure $5 \mathrm{~b}$ ). Neither SLO alone nor SLO in the presence of pro-gzmB had any effect on MEFs (Figure $5 a, b)$.

Treatment of MEFs with $5-20 \mu \mathrm{g} / \mathrm{ml} \mathrm{rgzmB}$ for $24 \mathrm{~h}$ led to a dose-dependent change in their morphology (Figure $5 \mathrm{c}$ ) and substantial cell death at $20 \mu \mathrm{g} / \mathrm{ml}$, but not at $5-10 \mu \mathrm{g} / \mathrm{ml}$ of rgzmB (Figure 5d). Incubation with pro-gzmB had no effect on MEFs morphology or viability (Figure $5 c$ and d, upper panels). In contrast, cell death of the non-adherent EL4 cell (regrowth) only occurred in response to both rgzmB and SLO, but neither to rgzmB or SLO alone nor to pro-gzmB plus SLO under these conditions (Figure $5 d$, lower panel). This suggests that cell death of MEFs occurring after long-term treatment with rgzmB is not induced directly, but rather as a consequence of cell detachment from the proteolytically degraded extracellular matrix.

To assess if mast cell-derived native gzmB has similar extracellular functions as the recombinant protein, MEFs were incubated for $20 \mathrm{~h}$ with serial dilutions of SN $(1: 2$ to $1: 16)$ from IgE-preloaded and DNP-HSA-stimulated (30 min) 
BMMC (Figure 6a). The gzmB-related proteolytic activity present in BMMC SN corresponded to $\sim 2 \mu \mathrm{g} / \mathrm{ml}$ of $\mathrm{rgzmB}$ (Figure $6 b$ ). As for the latter, a dose-dependent effect of BMMC SN was seen on the morphology and detachment of MEFs, which was most pronounced at the highest concentration of SN and inhibitable by the gzmB-specific inhibitor, AADcmk (Figure 6a). SN from either $\mathrm{gzmB}^{-1-}$ or control BMMC (mock-treated) did not have any effect. However, as expected from the results obtained with $2.5-5 \mu \mathrm{g} / \mathrm{ml} \mathrm{rgzmB}$ (24 h; Figure $5 c$ and d), induction of detachment and rounding up of MEFs by up to $2 \mu \mathrm{g} / \mathrm{ml}$ of native gzmB (as calculated in mast cell SN) was not associated with cell death (data not shown).

BMMC from $\mathrm{B} 6$, but not $\mathrm{gzmB}^{-1-}$ mice induce cell death in MEFs. Next, B6 and $\mathrm{gzmB}^{-1-}$ BMMCs were preloaded with anti-DNP $\operatorname{lgE}$ and incubated for $20 \mathrm{~h}$ with either the DNP-coated adherent MEFs or non-adherent EL4 cells; the viability of target cells was monitored by recultivation (Supplementary Figure $1 \mathrm{a}$ and b). Only B6, but not gzmB ${ }^{-1-}$ BMMCs showed a significant and dose-dependent induction of cell death of MEFs (Figure 7a), but did not induce any cell death of EL4 (Figure 7b), suggesting that gzmB is the prominent cytotoxic effector molecule.

A similar effect was observed when ex vivo-enriched LCMV-immune $\mathrm{CTL}^{7}$ from mice expressing only gzmB, but not perf and/or gzmA ( perfxgzmA ${ }^{-l-}$ ), were co-cultured with adherent cells (MC.Fas ${ }^{-1-}$, to exclude Fas-mediated toxicity) for prolonged periods $(20 \mathrm{~h})$. As shown in Figure $7 \mathrm{c}$, perfxgzmA ${ }^{-1-}$ CTL expressing only gzmB, but not perfxgzmAxB ${ }^{-1-} \mathrm{CTL}$, lacking in addition gzmB (Supplementary Figure 1d), showed a significant dose-dependent induction of cell death of MC.Fas ${ }^{-1-}$ cells (regrowth; Supplementary Figure 1c, for control). As expected, B6 CTL, which express the whole cytolytic armory, including perf and both gzms (Supplementary Figure 1d), killed the majority of MC.Fas ${ }^{-1-}$ cells under these conditions (Figure 7c).

GzmB induces a disorganization of endothelial cell-cell contacts. To assess the possibility of mast cell-released gzmB affecting endothelial cell-to-cell contacts, bEnd5 EC were treated with various concentrations of rgzmB and stained with antibodies binding VE-cadherin. In untreated EC, VE-cadherin showed a linear staining pattern at cellto-cell contacts (Figure 8a). Treatment with TNF- $\alpha$ and IFN- $\gamma$ resulted in morphological changes into elongated, spindlelike shapes of EC, as described previously (Figure 8a). ${ }^{22}$ Treatment with $\mathrm{rgzmB}(20 \mu \mathrm{g} / \mathrm{ml})$ resulted in disruption of cell-to-cell contacts and the appearance of multiple gaps in the monolayer (Figure 8a, right panel). A more detailed inspection of areas of cell-to-cell contact revealed that treatment with rgzmB, but not pro-gzmB, at $3 \mu \mathrm{g} / \mathrm{ml}$ resulted in a fragmented staining pattern for VE-cadherin (Figure $8 \mathrm{~b})$. At lower concentrations of $\operatorname{rgzmB}(0.3 \mu \mathrm{g} / \mathrm{ml})$, VE-cadherin fragmentation was less severe and similar to patterns observed with pro-gzmB. At higher concentrations of rgzmB $(20 \mu \mathrm{g} / \mathrm{ml})$, cell contacts appeared completely disorganized (Figure 8b, right panels). Furthermore, gzmBtreated bEnd.5 EC were stained with Ab against PECAM-1 and JAM-A, both of which are localized at sites of cell-to-cell contacts of $\mathrm{EC},{ }^{23}$ as well as for ZO-1, a cytoplasmic protein localized at tight junctions. Treatment of EC with $3 \mu \mathrm{g} / \mathrm{ml}$ rgzmB resulted in a reduced staining as well as in a fragmented staining pattern for PECAM-1, JAM-A and ZO-1 (Figure $8 \mathrm{c}$ ), without disturbing the integrity of the endothelial monolayer, as indicated by phase contrast microscopy (Supplementary Figure 2). The data suggest that mast cells affect endothelial cell-cell contacts via secreted gzmB thereby facilitating the recruitment of circulating leukocytes.

\section{Discussion}

Here, we show for the first time that mouse mast cells produce gzmB, but not gzmA or perf in vivo- as well as upon their differentiation from bone marrow cells (BMMC) in vitro. GzmB is associated in the lysosomal compartments of BMMC, and released in its enzymatically active form, together with other granule components, upon ligation of the receptors $\mathrm{Fc}_{\varepsilon} \mathrm{RI}$ and/ or c-kit. BMMC from B6, but not gzmB ${ }^{-1-}$ BMMC induced cell detachment and anoikis in anchorage-dependent MEF, suggesting a critical role of gzmB in this type of perfindependent killing. Although the usage of DNP to target $\mathrm{BMMC}$ to MEF via $\mathrm{FC}_{\varepsilon} \mathrm{R} 1$ in this model is artificial, it may reflect in vivo situations in which crosslinking of mast cellbound $\lg \mathrm{E} A b$ via antigen leads to rapid degranulation. We believe it is not unreasonable to assume that similar signaling pathways may be activated in vivo and lead to gzmBmediated effector functions of mast cells in biologically relevant situations. Also, rgzmB induces morphological changes in endothelioma cells, including a fragmented staining pattern of adhesion molecules, implicating mast cell-derived gzmB in the regulation of EC contact integrity. Therefore, gzmB of mast cells might influence not only the recruitment of leukocytes during inflammatory processes associated with protective, but also pathological immune responses.

Immunohistological staining revealed that $\mathrm{gzmB}$ is expressed in skin- but not lung-associated mast cells from naive mice. These observations are not surprising, in particular, in connection with recent reports showing that different environmental stimuli can determine quantity, distribution and phenotype of mast cells at selected tissue sites. ${ }^{1}$ The data presented in Figure 1 showing differential staining patterns observed with skin- versus lung-associated mast cells when using safranin and alcian blue support this contention. It is known that heparin-containing connective tissue mouse mast cells stain with both reagents, whereas the chondroitin sulfate-containing mucosal mast cells are only stained by alcian blue. ${ }^{15}$ Although both skin and lung tissue are primary target sites for host/pathogen contact, our data suggest that the mast cell phenotype found in diverse tissues, including gzmB expression, is determined by multiple factors, including physiological, inflammatory and microbial ones.

In BMMC, gzmB is associated with secretory lysosomes, that is, cytoplasmic granules, similar to that seen in CTL/NK (Figure 3). ${ }^{5}$ We found that gzmB colocalizes, primarily, with Lamp-1-positive (lysosomal marker) ${ }^{18}$ vesicles of BMMC and is secreted upon FceR1/c-kit-mediated activation. This suggests that processing and assortment of gzmB to the 
cytoplasmic granules, including its storage in a complex with the proteoglycan serglycin, occurs similar to that observed in CTL/NK cells. ${ }^{24}$ This interpretation is supported by the finding that mast cell proteases are also stored as active enzymes in lysosomal compartments ${ }^{25,26}$ and that the mast cell tryptase, mMCP-6, accumulates in and is released from granules in association with serglycin. ${ }^{27}$
In contrast to our data with BMMC, neoplastic human mast cells may aquire a cytolytic effector profile through combined gzmB plus perf expression upon activation with PMA and ionomycin (J. A. Kummer, abstract 035, Apoptosis and Immunity 2005, Palm Cove, Australia). It is not clear if the differential production of perf in human versus mouse mast cells is due to the distinct activation protocols or due to variant a
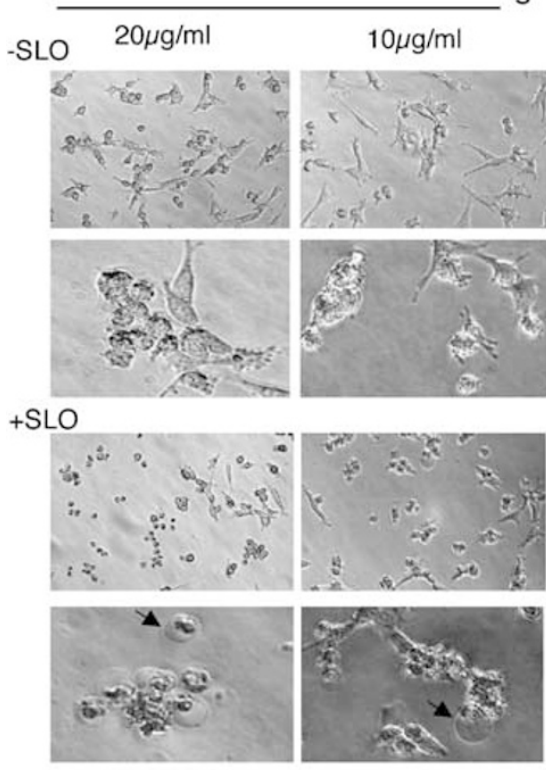

SLO
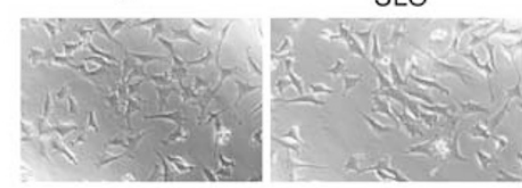

rgzmB

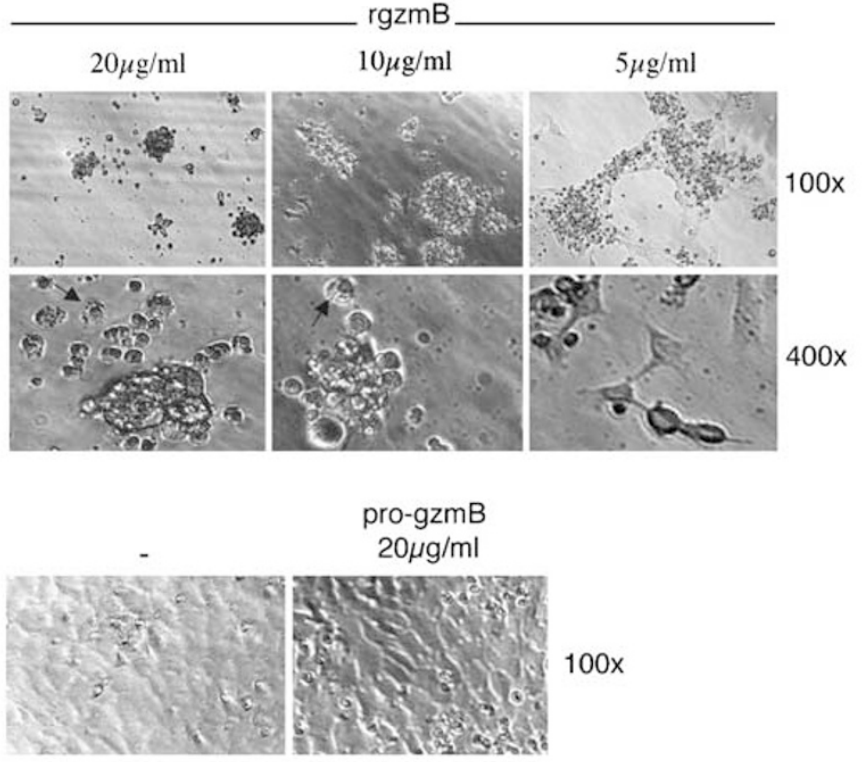

rgzmB
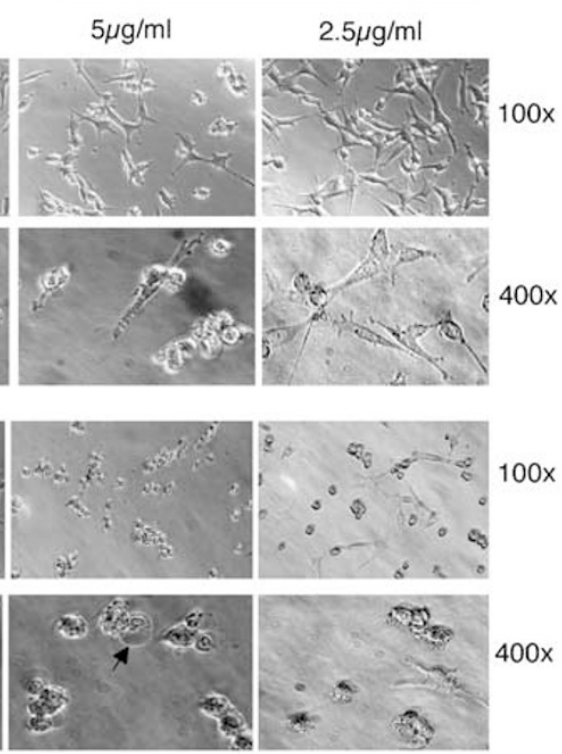

pro-gzmB $\quad \mathrm{SLO}+$ pro-gzmB

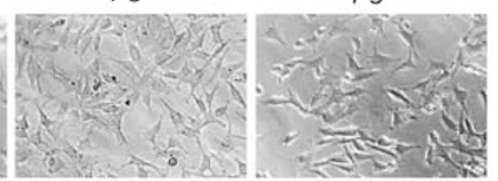

$100 x$ b
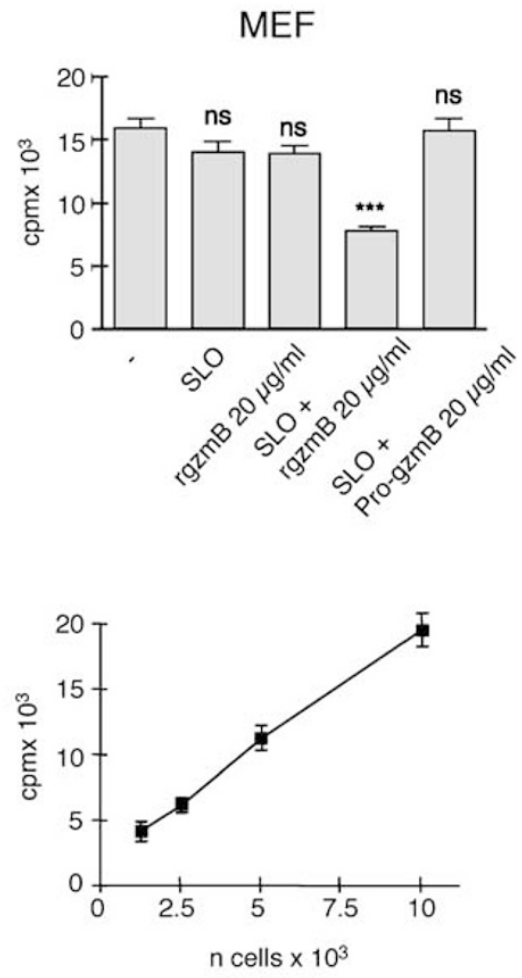

MEF d

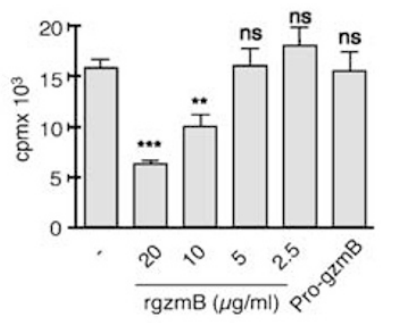

EL4

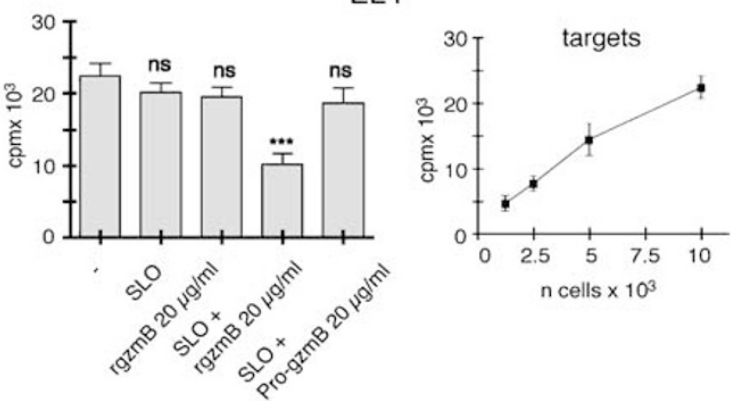


transcriptional regulatory events occurring in these two species. However, we cannot exclude the possibility that mouse mast cells may express perf in addition to gzmB under different conditions. BMMC, unlike CTL/NK cells, also did not express gzmA. It is possible that the tryptase, mMCP-6, with similar substrate specificity to that of gzmA, but distinct from gzmB, ${ }^{8,27}$ may substitute for gzmA in mast cell-induced biological processes. Thus, mMCP- 6 and gzmB not only may execute differing nonredundant extracellular processes reminiscent of gzmA and gzmB from CTL/NK cells, ${ }^{8-10}$ but may also act in concert with gzmB on the same substrates, such as fibronectin, although with distinct cleavage specificities. ${ }^{8,10,28}$

Activated BMMC from B6 but not $\mathrm{gzmB}^{-1-}$ mice caused cell death in adherent MEFs (Figure 7a), but not anchorageindependent EL4 cells (Figure 7b). This implicates gzmB in perf-independent cytolysis (anoikis). ${ }^{10}$ Recombinant and native human gzmB cleaves the extracellular matrix proteins, vitronectin, fibronectin and laminin, resulting in cell detachment and cell death of adherent targets, including inhibition of tumor cell spreading, migration and invasion. ${ }^{10}$ Thus, BMMC may induce anoikis, in susceptible targets, indirectly, by gzmB-mediated degradation of extracellular matrix proteins. That $\mathrm{gzmB}^{-1-} \mathrm{BMMC}$ lack this selective function and that B6 BMMC do not express gzms A, C, D, E, F, $\mathrm{G}, \mathrm{K}$ and/or $\mathrm{M}$ (Figure 3 and data not shown), supports this assumption. However, the contribution of other proteases, like mMCP-6, known to promote proteolytic degradation of fibronectin, with a cleavage specificity similar to gzmA, but distinct from $g z m B,{ }^{8,10,28}$ in these processes can not be formally excluded.

We also observed that virus immune CTL from perfxgzmA $\mathrm{A}^{-1-}$ mice, which express gzmB but lack gzmA and perf, but not CTL from perfxgzmAxB ${ }^{-1-}$ mice, which lack perf and both gzms, are able to induce anoikis in adherent cells (Figure 7c, d) like BMMC. This suggests that NK/CTL also can induce anoikis in susceptible target cells, solely via gzmB and independent of perf. This may be explanatory for understanding the immune status of perf deficient individuals, such as patients with familial hemophagocytic lymphohistiocytosis $(\mathrm{FHL}){ }^{29}$ It could be expected that FHL patients have residual NK/CTL-associated cytolytic potential and normal mast cell functions.

Mast cells are known to seed in close proximity to EC of blood vessels ${ }^{30}$ and may directly act on EC and SMC, via secreted factors, including pro-inflammatory cytokines and chemokines. $^{30-32}$ The observation that BMMC secrete gzmB and that rgzmB induces disintegration of EC-cell-cell contacts at concentrations where gross morphological changes and EC detachment are not yet observed $(3 \mu \mathrm{g} / \mathrm{ml})$, may indicate that mast cell-derived gzmB contributes to the recruitment of leukocytes by facilitating their transendothelial migration. ${ }^{33}$ Evidence that intraperitoneal administration of mMCP-6 results in neutrophil infiltration into the peritoneum ${ }^{27}$ supports the idea of a general role for mast cell-derived proteases in leukocyte recruitment.

Most probably, gzmB acts on EC indirectly by cleaving ECM proteins, like fibronectin, vitronectin or laminin. ${ }^{10}$ In fact, proteolysis of ECM proteins affects integrin-mediated cellmatrix adhesion leading to subsequent cell detachment and death. ${ }^{34}$ Thus, the previous finding that integrin-mediated signaling directly influences VE-cadherin-based adherens junctions ${ }^{35}$ suggests a potential mechanism by which gzmB influences cell-cell contact integrity.

As observed previously by Buzza and Choy, ${ }^{10,36}$ we found extensive EC detachment at high gzmB concentrations $(20 \mu \mathrm{g} / \mathrm{ml})$ evident by multiple gaps in the endothelial monolayer. Thus, mast cell-derived gzmB may be responsible for cell detachment of EC, leading to their death, a feature seen in the pathogenesis of atherosclerosis. ${ }^{37}$ In fact, atherosclerotic lesions in human coronary arteries have been shown to contain elevated numbers of mast cells ${ }^{38}$ and an increased severity and cell death in advanced atherosclerotic lesions was associated with a presence of gzmB. ${ }^{39}$ Furthermore, mast cell-derived gzmB may also contribute to vasculitis by inducing cell death in SMC, as reported. ${ }^{11}$ However, only testing of atherosclerosis development in gzmB-deficient mice may provide evidence for the role of mast cell-derived gzmB in vascular diseases in vivo.

Mast cells have been implicated in the control of bacterial and viral infections, ${ }^{31,32}$ immunosurveillance, in disease progression $^{1,3,30}$ and, more recently, as intermediaries in regulatory $\mathrm{T}$ cell tolerance. ${ }^{40}$ However, the role gzmB may play in any of these processes is unknown. Recent evidence implicates mast cell-derived gzmB in the inhibition of tumorigenesis. ${ }^{1,3,10}$ Mast cell-secreted gzmB may also assist in the control of virus infections by either cleaving viral surface proteins critical for host cell entry, ${ }^{10}$ or by inducing anoikis in gzmB-susceptible virus-infected target cells. Mast cell migration and accumulation at sites of viral infections supports this contention. ${ }^{30}$

The presence of mast cells and gzmB-positive cells at the invasive front of the synovium and elevated levels of gzmB in serum and synovial fluids is a hallmark of patients with active

Figure 5 rgzmB induces cell death in fibroblasts via cell detachment. (a, b) MEFs were plated before treatment (triplicates) with the indicated amounts of rgzmB or pro$\mathrm{gzmB}$ in the absence or presence of a sublytic dose of SLO $(0.5 \mu \mathrm{g} / \mathrm{ml})$ for $4 \mathrm{~h}$ or were left untreated (medium). Representative microscopic images were taken from corresponding wells (a). Cell survival was monitored by recultivating MEFs and determination of ${ }^{3} \mathrm{H}$-thymidine incorporation as described in Materials and methods (b, upper panel). Percentage of cell death was calculated from log2 titration curve of untreated MEFs (b, lower panel). Data are given as mean \pm S.E.M. of three independent experiments performed by triplicate. ${ }^{* \star}$ Significantly different, $P=0.0001$. ns, not significant. (c, d) MEFs were plated before treatment with the indicated amounts of rgzmB and/or pro-gzmB for $24 \mathrm{~h}$ (triplicates) and analyzed as in (a, b). In addition, non-adherent EL4 cells were treated with the indicated amounts of rgzmB or pro-gzmB in the absence or presence of a sublytic dose of SLO $(0.5 \mu \mathrm{g} / \mathrm{ml})$ for $24 \mathrm{~h}$ (d, lower panels). Cell survival was monitored by recultivating treated EL4 cells and determination of ${ }^{3} \mathrm{H}$ thymidine incorporation. Percentage of cell death was calculated from log2 titration curve of untreated EL4 cells (d, lower panels). Data are given as mean \pm S.E.M. of three independent experiments for MEF and two for EL4 (triplicates). (b) ${ }^{* * *},{ }^{* *}$ significantly different, $P<0.0001$ or 0.0011 , respectively for MEF and ${ }^{* * *}, P=0.0003$ for EL4. ns, not significant. Analyzed by unpaired two-tailed $t$-test comparing medium with treated cells. Images were taken at room temperature using a Zeiss Axiovert 10 microscope, a Zeiss Axiocam as analysis camera, and Zeiss Vision 3.1.0.0 as software (Carl Zeiss, Jena, Germany). The objective used was a Zeiss ACHROSTIGMAT, with original magnification $\times 100$ (NA 0.25) or $\times 320$ (NA 0.4). Photoshop CS2 software (Adobe) was used for minor adjustments to contrast. Arrows indicate apoptotic- (a) or non apoptotic- (c) like dead cells 
a

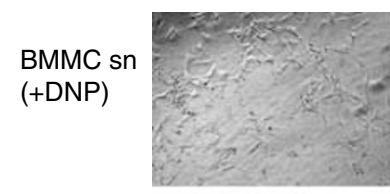

$+A A D$

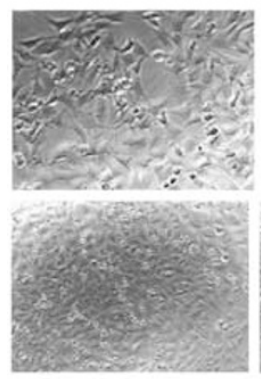

$-$

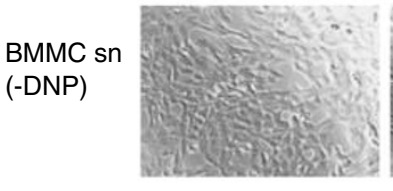

-
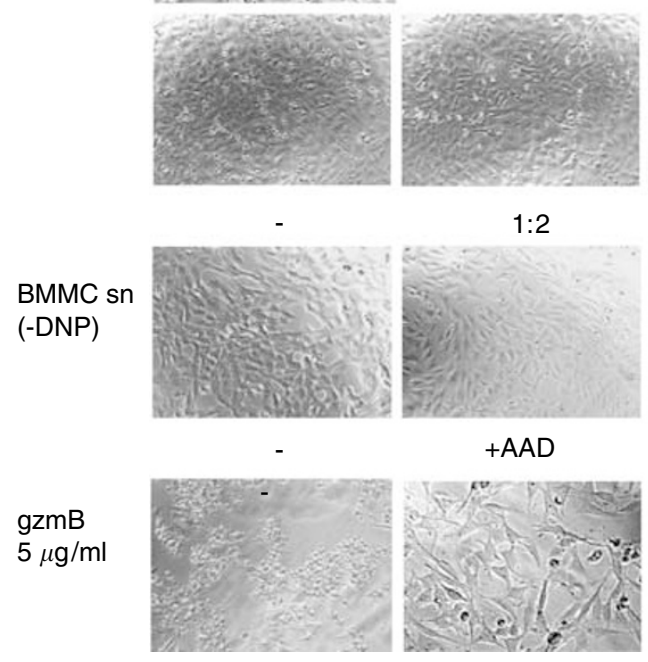

$1: 2$
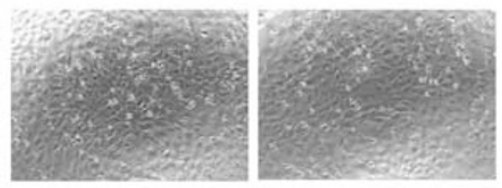

$\mathrm{gzmB}^{-/-}$

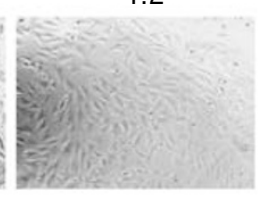

$+\mathrm{AAD}$

b
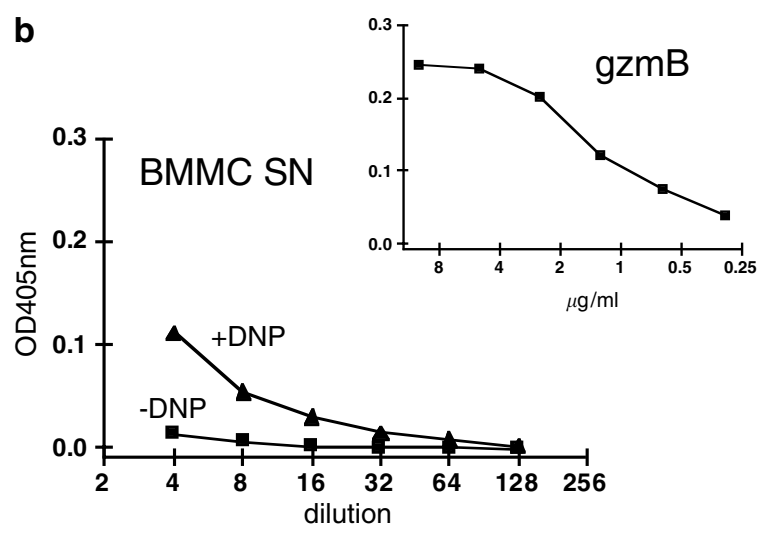

Figure 6 Supernatants of activated mast cells induce cell detachment. BMMCs from B6 or gzmB ${ }^{-1}$ mice, previously loaded with DNP-specific lgE, were incubated in the presence or absence of DNP-HSA for $30 \mathrm{~min}$ and SN were collected. (a) Attached MEFs were incubated with the indicated dilutions of SN from DNP-HSA- or mock-treated BMMC or with $5 \mu \mathrm{g} / \mathrm{ml} \mathrm{rgzmB}$ for $20 \mathrm{~h}$. To inhibit the enzymatic activity of gzmB, SN of DNP-HSA-treated B6 BMMC (1:2 dil) and rgzmB were in addition incubated with AAD$\mathrm{cmk}(100 \mu \mathrm{M})$ for $30 \mathrm{~min}$ before usage. Representative microscopic images were taken from corresponding wells as described in Figure 3 (original magnification $\times 100$ ). (b) GzmB activity was tested in SN as described in Figure 2. rGzmB served as control. Data are given as mean \pm S.E.M. of two independent experiments

rheumatoid arthritis (RA). ${ }^{13,41,42}$ The finding of degranulated mast cells in joint tissue of mice with experimentally induced erosive synovitis and the observation that two strains of mice deficient in mast cells were resistant to the development of this type of joint inflammation ${ }^{43}$ points to a likely role of mast cells in the pathogenesis of inflammatory arthritides, including RA. ${ }^{44}$ Thus, mast cell-derived gzmB may contribute, together with other granule-associated effector molecules and mediators, to the pathogenic mechanisms of joint destruction by facilitating recruitment of leukocytes from the circulation, ${ }^{31,32}$ degrading cartilage proteoglycan ${ }^{14}$ and/or by killing synovial membrane lining cells, most probably via anoikis. ${ }^{11}$

\section{Materials and Methods}

Flow cytometry. Cell populations were analyzed for cell surface marker expression and/or intracellular expression of gzmA and gzmB by FACS as described previously. ${ }^{17}$ Abs are described in Supplementary material. 


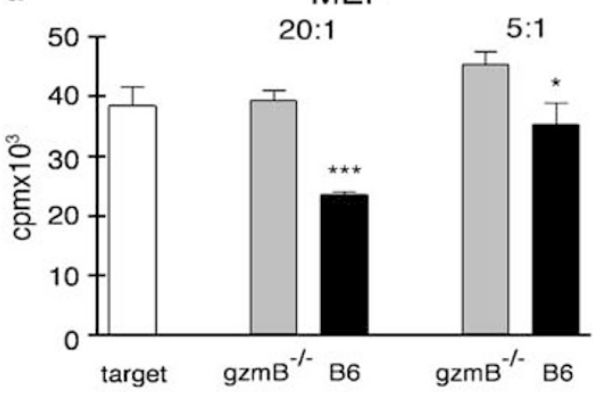

C

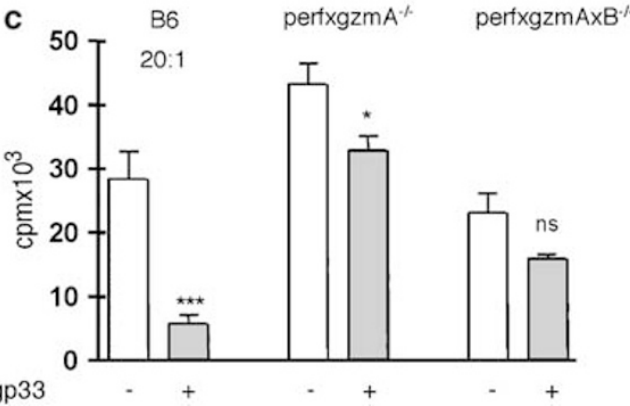

b
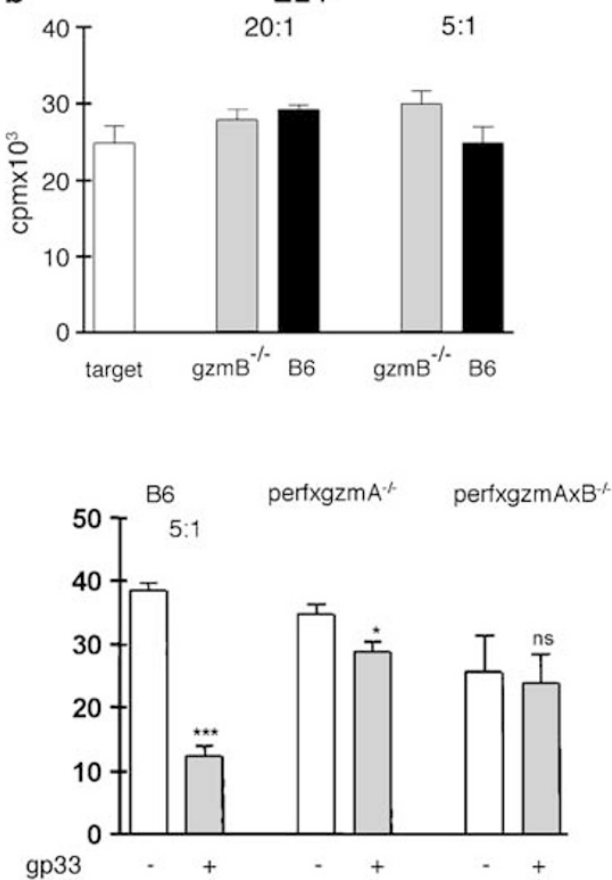

Figure 7 Intact mast cells from $\mathrm{B} 6$, but not from $\mathrm{gzmB}^{-1-}$ mice are able to kill MEF. BMMCs were generated from $\mathrm{B} 6$ or gzmB ${ }^{-1-}$ mice and incubated in triplicates with DNP-labeled MEF (a) or EL4 (b) at indicated effector : target ratios for $20 \mathrm{~h}$ as described in Materials and methods. Survival of target cells was analyzed by ${ }^{3} \mathrm{H}$-thymidine incorporation as described in Materials and methods. Data are given as mean \pm S.E.M. of two independent experiments performed by triplicate. ${ }^{* * *},{ }^{*}$ significantly different, $P<0.0001$ or $P=0.035$, respectively. ns, not significant. Analyzed by unpaired two-tailed $t$-test comparing wt with gzmB ${ }^{-l-}$. When comparing effector: target ratios of $5: 1$ and $20: 1$, significant differences are only found for wt $(P=0.008)$, but not for gzmB ${ }^{-1-}(P=0.053)$ BMMC. Analyzed by unpaired two-tailed $t$-test. (c) Ex vivo-derived LCMVimmune CTL from B6, perfxgzmA ${ }^{-1}$ or perfxgzmAxB ${ }^{-1-}$ mice were generated as described previously ${ }^{7}$ and incubated with MCFas ${ }^{-1-}$ for $20 \mathrm{~h}$ with $(+)$ or without $(-)$ gp33 peptide, at effector : target ratios of 20:1 (left panel) and 5:1 (right panel). Survival of target cells was analyzed by ${ }^{3} \mathrm{H}$-thymidine incorporation as described previously. ${ }^{1}$ Data are given as mean \pm S.E.M. of two independent experiments performed by triplicate. Ratio $20: 1$, ${ }^{\star \star *}$, ${ }^{*}$ significantly different, $P=0.0004$ or $P=0.0304$, respectively. ns, not significant. Ratio $5: 1,{ }^{* * *}$, ${ }^{*}$ significantly different, $P<0.0001$ or $P=0.0262$, respectively. ns, not significant. Analyzed by unpaired two-tailed $t$-test comparing - gp33 with $+\mathrm{gp} 33$

Western blot analysis. Intracellular gzmA, gzmB, perf and actin were determined in cell lysates by WB under reducing conditions, as described previously. ${ }^{17}$ Abs are described in Supplementary material.

Probing for mRNA expression. Total RNA was extracted from up to $5 \times 10^{6}$ cells, using the QIAshredder spin columns, the RNeasy Mini Kit and the RNase-free DNase Kit (all from Qiagen, Hilden, Germany), according to manufacturers instructions, and specific transcripts were amplified as described in Supplementary material.

Enzymatic assays. Proteolytic activity of gzmB using the colorimetric substrate Ac-lle-Glu-Pro-Asp-pNA (Bachem, Weil am Rhein, Germany) was performed as described previously. ${ }^{17}$

Mast cell degranulation assays. BMMC were preloaded overnight with DNP-specific lgE $(0.2 \mu \mathrm{g} / \mathrm{ml}$, clone SPE-7; SIGMA, Deisenhofen, Germany) and subsequently stimulated with antigen (DNP-HSA, containing 30-40 moles DNP per mol albumin, $(20 \mathrm{ng} / \mathrm{ml}$; SIGMA, Deisenhofen, Germany) or SCF $(100 \mathrm{ng} / \mathrm{ml})$ or a combination of both in RPMl 1640 without phenol red containing $10 \mathrm{mM}$ Hepes $(\mathrm{pH}$ 7.4 ) and $2 \mathrm{mg} / \mathrm{ml} \mathrm{BSA}\left(10^{6} \mathrm{cell} / \mathrm{s} / \mathrm{ml}\right)$ in duplicates or triplicates for $30 \mathrm{~min}$ at $37^{\circ} \mathrm{C}$. $\mathrm{SN}$ were collected and stored at $-80^{\circ} \mathrm{C}$ until usage for determination of gzmB enzymatic activity. The degree of degranulation was determined by measuring the activity of released (sup) and cellular (pel) $\beta$-hexosaminidase. ${ }^{45}$ Percentage of degranulation was calculated using the following formula: \%degr $=$ [activity(sup)/ (activity(sup) $+\operatorname{activity}($ pel) $)] \times 100$

Cell detachment and cytotoxicity induced by recombinant gzmB

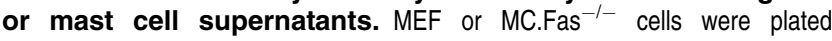

( $2 \times 10^{4} \mathrm{cell} /$ well, triplicates, 96-well plates) and cultured overnight in MEM $(+5 \%$ FCS $)$. Adherent cells were washed with PBS $(\times 2)$ and incubated with the indicated amounts of the following preparations: pro-gzmB, gzmB, SN from mast cells, SLO ${ }^{46}$ or mixtures of SLO and pro-gzmB or gzmB, for $4 \mathrm{~h}$ or $24 \mathrm{~h}$. In some experiments, gzmB or mast cell SN were pre-incubated with $100 \mu \mathrm{M}$ AAD-cmk (Bachem) for $30 \mathrm{~min}$ at $37^{\circ} \mathrm{C}$ to inactivate gzmB. Following treatment for $4 \mathrm{~h} / 24 \mathrm{~h}$, survival of MEFs/MC.Fas ${ }^{-1}$ cells was monitored as described previously. ${ }^{47} \mathrm{~A}$ similar assay was used for treatment and monitoring non-adherent EL4 cells. For each cell line, sublytic doses of SLO were determined, before further testing.

Immunofluorescence. Cell lines and ex vivo-derived LCMV-immune CTL were analyzed by confocal microscopy, as described previously. ${ }^{48}$

bEnd.5 endothelioma cells were grown on LabTek chamber slides (NalgeneNunc, Wiesbaden, Germany) and stained as described previously. ${ }^{49}$ Phase contrast microscopy was performed on a Leica DM RXA microscope (Leica Microsystems, Wetzlar Germany). Abs are described in Supplementary material.

BMMC-mediated cytotoxicity. MEFs were added to 96-well plates $\left(2 \times 10^{4}\right.$ cell/well in triplicates) and cultured overnight in MEM (5\% FCS). Adherent cells were washed twice with PBS, treated with $100 \mu \mathrm{l} \mathrm{PBS} / 4 \mathrm{mM}$ DNB$\mathrm{S}$ for $10 \mathrm{~min}$ at $37^{\circ} \mathrm{C}$, and washed again $(2 \times)$ with MEM (5\% FCS), followed by MEM, supplemented with $2 \mathrm{mg} / \mathrm{ml} \mathrm{BSA}$ and $100 \mathrm{ng} / \mathrm{ml}$ SCF. BMMCs, preloaded with $\mathrm{mAb} \operatorname{lgE}$ (see above) were added to DNB-S-labeled MEFs and incubated for $24 \mathrm{~h}$. Subsequently, SNs were removed and percentages of survival of the attached cells were quantified by ${ }^{3} \mathrm{H}$-thymidine incorporation and comparison of values to those from proliferation rates of log2 dilutions of the respective cell line as described previously. ${ }^{47}$ 
a VE-cadherin
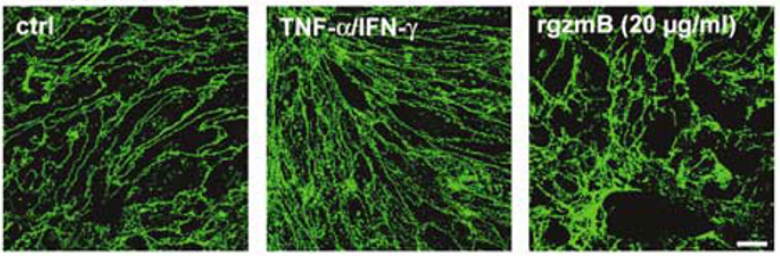

b VE-cadherin
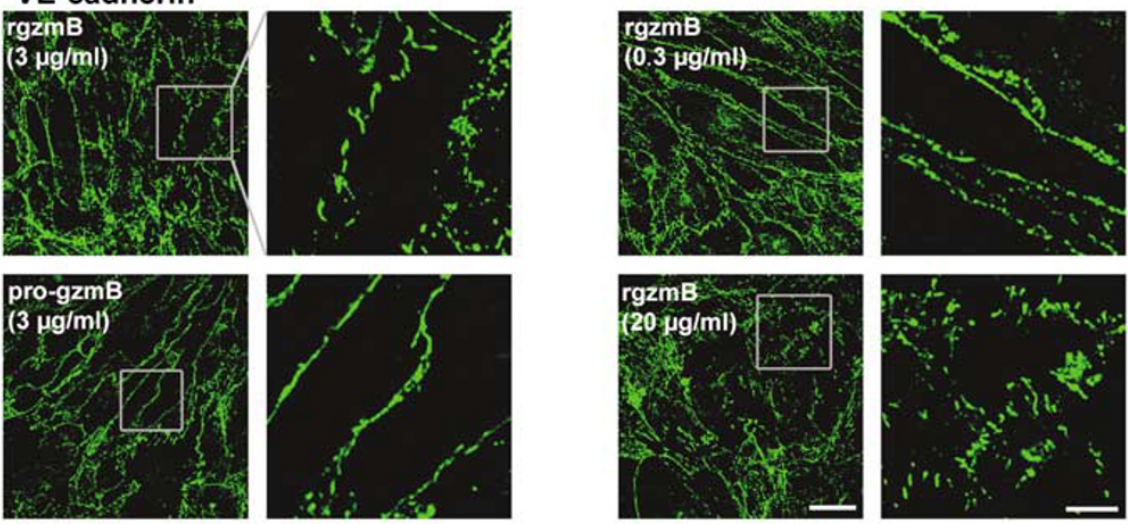

\section{c PECAM-1}

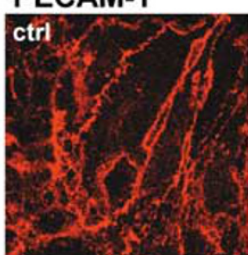

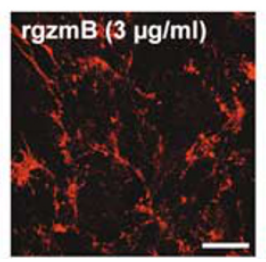
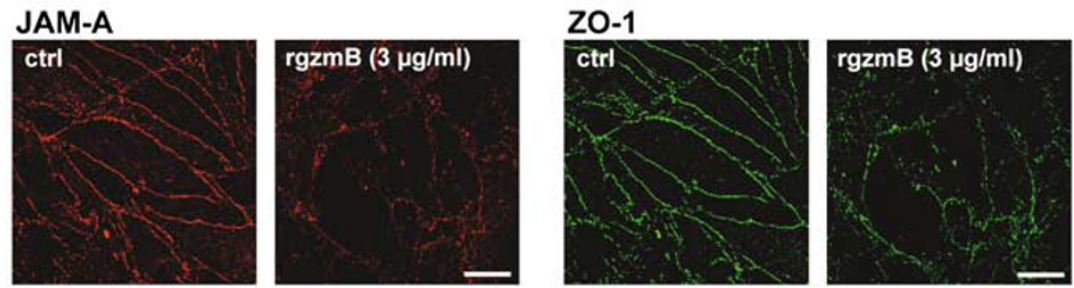

Figure $8 \mathrm{GzmB}$ induces a disorganization of endothelial cell-cell contacts. (a) bEnd.5 EC were treated with $20 \mu \mathrm{g} / \mathrm{ml} \mathrm{gzmB}$ for $24 \mathrm{~h}$, then fixed and stained for VEcadherin. Control cells were either left untreated (ctrl) or incubated with a combination of TNF- $\alpha$ and IFN- $\gamma(1000 \mathrm{U} / \mathrm{ml}$ each). Note that gzmB treatment results in multiple gaps in the EC monolayer. Bar, $20 \mu \mathrm{m}$. (b) bEnd.5 EC were incubated for $24 \mathrm{~h}$ with the indicated concentrations of active gzmB or with $3 \mu \mathrm{g} / \mathrm{ml}$ of inactive gzmB (pro-gzmB) and stained for VE-cadherin. The right panels reflect magnifications of the regions delineated by the gray insets. GzmB treatment disrupts the linear staining pattern of VE-cadherin in a dose-dependent manner. Bars: left panels, $20 \mu \mathrm{m}$; right panels; $5 \mu \mathrm{m}$. (c) bEnd. $5 \mathrm{EC}$ were incubated with $3 \mu \mathrm{g} / \mathrm{ml}$ gzmB for $24 \mathrm{~h}$ and stained with Ab against PECAM-1, JAM-A and ZO-1. GzmB treatment results in a fragmented staining pattern of all three molecules. Bars, $20 \mu \mathrm{m}$

For treatment of EL4, $6 \times 10^{5}$ cells were incubated with $500 \mu \mathrm{l}$ of PBS $/ 4 \mathrm{mM}$ DNB-S for $10 \mathrm{~min}$ at $37^{\circ} \mathrm{C}$, washed with MEM $(5 \% \mathrm{FCS} ; \times 2)$ and resuspended in MEM supplemented with $2 \mathrm{mg} / \mathrm{ml} \mathrm{BSA}+100 \mathrm{ng} / \mathrm{ml} \mathrm{SCF}$. A $2 \times 10^{4}$ portion of cells was seeded in 96-well plates (triplicates) and incubated with $\mathrm{mAb} \operatorname{lgE}$ pre-loaded BMMCs for $24 \mathrm{~h}$. Survival of EL 4 cells was quantified by ${ }^{3} \mathrm{H}$-thymidine incorporation as described previously. ${ }^{47}$ BMMCs are unable to proliferate in the absence of IL-3.

CTL-mediated cytotoxicity. Plated MC.Fas ${ }^{-1-}$ cells were pretreated with the LCMV-immunodominant peptide gp33 for $2 \mathrm{~h}$ before incubation with ex vivoderived LCMV-immune CTLs from B6, perfxgzmA ${ }^{-1-}$ and perfxgzmAxB ${ }^{-1-}$ at indicated effector : target cell ratios for $24 \mathrm{~h}$, as described previously. ${ }^{7}$ Cell survival was quantified by ${ }^{3} \mathrm{H}$-thymidine incorporation as described previously. ${ }^{47}$

Histological and immunohistological analysis. Skin and lung tissues from naive C57BL/6 (B6) mice were removed and fixed in phosphate-buffered saline (PBS plus formaldehyde, $4 \%$ ) before being embedded in paraffin. Sections were stained with alcian blue alone or counterstained with safranin as described previously. ${ }^{15}$ Photomicrographs were taken by using a Zeiss microscope provided with an Axiocam camara and Axiovision software.

Alcian blue-stained secions were used for immunostaining for gzmB expression. Accordingly, sections were incubated with $0.6 \% \mathrm{H}_{2} \mathrm{O}_{2}(30 \mathrm{~min})$ in methanol to block endogenous peroxidase, followed by treatment ( $3 \mathrm{~h}$ at room temperature) with $5 \%$ goat serum in Roti-Block buffer (Roth, Karlsruhe, Germany). Next, consecutive sections were incubated at $4^{\circ} \mathrm{C}$ overnight either with rabbit anti-gzmB or -gzmA IgG or with control rabbit IgG (1:200 diluted in Roti-Block). After thorough washing, sections were further incubated ( $2 \mathrm{~h}$ at room temperature) with goat anti-rabbit lgG as secondary antibody, labeled with horseradish peroxidase. After washing, slides were incubated $(1 \mathrm{~h})$ with diaminobenzidine (Sigma), followed by addition of $0.3 \%$ $\mathrm{H}_{2} \mathrm{O}_{2}$ (15-20 min). Photomicrographs were taken by using a Zeiss microscope provided with an Axiocam camara and Axiovision software.

Acknowledgements. We thank Sucharit Bhakdi for his generous gift of streptolysin. JP was supported by a grant from the Alexander von Humboldt Foundation and AM by a grant from the National Health \& Medical Research Counci of Australia.

\section{Note added in proof}

During the course of the reviewing process, a study appeared demonstrating that human mast cells produce gzmB in vivo and in vitro and release it upon activation. ${ }^{50}$

1. Metz M, Maurer M (2007) Mast cells - key effector cells in immune responses. Trends Immunol 28: 234-241.

2. Marshall JS (2004) Mast-cell responses to pathogens. Nat Rev Immunol 4: 787-799.

3. Gall SJ, Nakae S, Tsai M (2005) Mast cells in the development of adaptive immune responses. Nat Immunol 6: 135-142. 
4. Kataoka TR, Morii E, Oboki K, Kitamura Y (2004) Strain-dependent inhibitory effect of mutant mi-MITF on cytotoxic activities of cultured mast cells and natural killer cells of mice. Lab Invest 84: 376-384.

5. Russell JH, Ley TJ (2002) Lymphocyte-mediated cytotoxicity. Annu Rev Immunol 20 323-370.

6. Stinchcombe JC, Bossi G, Booth S, Griffiths GM (2001) The immunological synapse of CTL contains a secretory domain and membrane bridges. Immunity 15: 751-761.

7. Pardo J, Bosque A, Brehm R, Wallich R, Naval J, Mullbacher A et al. (2004) Apoptotic pathways are selectively activated by granzyme $A$ and/or granzyme $B$ in CTL-mediated target cell lysis. J Cell Biol 167: 457-468.

8. Simon MM, Ebnet K, Kramer MD (1993) Molecular analysis and possible pleiotropic function(s) of the T cell-specific serine proteinase $1 \mathrm{In}$ : Sitkovsky MV, Henkart PA (eds). Cytotoxix Cells: Recognition, Effector Function, Generation, and Methods. Birkhäuser: Boston, Basel, Berlin pp 278-294.

9. Suidan HS, Bouvier J, Schaerer E, Stone SR, Monard D, Tschopp J (1994) Granzyme A released upon stimulation of cytotoxic $T$ lymphocytes activates the thrombin receptor on neuronal cells and astrocytes. Proc Natl Acad Sci USA 91: 8112-8116.

10. Buzza MS, Zamurs L, Sun J, Bird CH, Smith Al, Trapani JA et al. (2005) Extracellular matrix remodeling by human granzyme $B$ via cleavage of vitronectin, fibronectin, and laminin J Biol Chem 280: 23549-23558.

11. Choy JC, Hung VH, Hunter AL, Cheung PK, Motyka B, Goping IS et al. (2004) Granzyme B induces smooth muscle cell apoptosis in the absence of perforin: involvement of extracellular matrix degradation. Arterioscler Thromb Vasc Biol 24: 2245-2250.

12. Simon MM, Simon HG, Fruth U, Epplen J, Muller-Hermelink HK, Kramer MD (1987) Cloned cytolytic T-effector cells and their malignant variants produce an extracellular matrix degrading trypsin-like serine proteinase. Immunology 60: 219-230.

13. Tak PP, Spaeny-Dekking L, Kraan MC, Breedveld FC, Froelich CJ, Hack CE (1999) The levels of soluble granzyme $A$ and $B$ are elevated in plasma and synovial fluid of patients with rheumatoid arthritis (RA). Clin Exp Immunol 116: 366-370.

14. Froelich CJ, Zhang X, Turbov J, Hudig D, Winkler U, Hanna WL (1993) Human granzyme B degrades aggrecan proteoglycan in matrix synthesized by chondrocytes. $J$ Immunol 151: 7161-7171.

15. Stevens RL, Rothenberg ME, Levi-Schaffer F, Austen KF (1987) Ontogeny of in vitrodifferentiated mouse mast cells. Fed Proc 46: 1915-1919.

16. Gimborn K, Lessmann E, Kuppig S, Krystal G, Huber M (2005) SHIP down-regulates FcepsilonR1-induced degranulation at supraoptimal IgE or antigen levels. J Immunol 174: 507-516.

17. Martin P, Wallich R, Pardo J, Mullbacher A, Munder M, Modolell M et al. (2005) Quiescent and activated mouse granulocytes do not express granzyme $A$ and $B$ or perforin similarities or differences with human polymorphonuclear leukocytes? Blood 106: 2871 2878.

18. Chen JW, Pan W, D'Souza MP, August JT (1985) Lysosome-associated membrane proteins: characterization of LAMP-1 of macrophage P388 and mouse embryo 3T3 cultured cells. Arch Biochem Biophys 239: 574-586.

19. Tschopp J, Nabholz M (1990) Perforin-mediated target cell lysis by cytolytic T lymphocytes. Annu Rev Immunol 8: 279-302.

20. Schwartz LB, Austen KF (1980) Enzymes of the mast cell granule. J Invest Dermatol 74 349-353.

21. Huber M, Helgason CD, Scheid MP, Duronio V, Humphries RK, Krystal G (1998) Targeted disruption of SHIP leads to Steel factor-induced degranulation of mast cells. EMBO J 17: 7311-7319.

22. Rival Y, Del Maschio A, Rabiet MJ, Dejana E, Duperray A (1996) Inhibition of platelet endothelial cell adhesion molecule-1 synthesis and leukocyte transmigration in endothelial cells by the combined action of TNF-alpha and IFN-gamma. J Immunol 157: 1233-1241.

23. Dejana E (2004) Endothelial cell-cell junctions: happy together. Nat Rev Mol Cell Biol 5 261-270.

24. Raja SM, Metkar SS, Froelich CJ (2003) Cytotoxic granule-mediated apoptosis: unraveling the complex mechanism. Curr Opin Immunol 15: 528-532.

25. Dikov MM, Springman EB, Yeola S, Serafin WE (1994) Processing of procarboxypeptidase A and other zymogens in murine mast cells. J Biol Chem 269: 25897-25904.

26. Salvesen G, Enghild JJ (1990) An unusual specificity in the activation of neutrophil serine proteinase zymogens. Biochemistry 29: 5304-5308.
27. Huang C, Friend DS, Qiu WT, Wong GW, Morales G, Hunt J et al. (1998) Induction of a selective and persistent extravasation of neutrophils into the peritoneal cavity by tryptase mouse mast cell protease 6. J Immunol 160: 1910-1919.

28. Hallgren J, Spillmann D, Pejler G (2001) Structural requirements and mechanism for heparin-induced activation of a recombinant mouse mast cell tryptase, mouse mast cell protease-6: formation of active tryptase monomers in the presence of low molecular weight heparin. J Biol Chem 276: 42774-42781.

29. Stepp SE, Dufourcq-Lagelouse R, Le Deist F, Bhawan S, Certain S, Mathew PA et al. (1999) Perforin gene defects in familial hemophagocytic lymphohistiocytosis. Science 286: 1957-1959.

30. Marshall JS, Jawdat DM (2004) Mast cells in innate immunity. J Allergy Clin Immunol 114: 21-27.

31. Echtenacher B, Mannel DN, Hultner L (1996) Critical protective role of mast cells in a model of acute septic peritonitis. Nature 381: 75-77.

32. Malaviya R, Ikeda T, Ross E, Abraham SN (1996) Mast cell modulation of neutrophil influx and bacterial clearance at sites of infection through TNF-alpha. Nature 381: 77-80.

33. Nourshargh S, Marelli-Berg FM (2005) Transmigration through venular walls: a key regulator of leukocyte phenotype and function. Trends Immunol 26: 157-165.

34. Meredith, Jr JE, Fazeli B, Schwartz MA (1993) The extracellular matrix as a cell survival factor. Mol Biol Cell 4: 953-961.

35. Wang Y, Jin G, Miao H, Li JY, Usami S, Chien S (2006) Integrins regulate VE-cadherin and catenins: dependence of this regulation on Src, but not on Ras. Proc Natl Acad Sci USA 103: $1774-1779$.

36. Choy JC, Cruz RP, Keriner A, Geisbrecht J, Sawchuk T, Fraser SA et al. (2005) Granzyme $B$ induces endothelial cell apoptosis and contributes to the development of transplant vascular disease. Am J Transplant 5: 494-499.

37. Hansson GK, Libby $P$ (2006) The immune response in atherosclerosis: a double-edged sword. Nat Rev Immunol 6: 508-519.

38. Kaartinen M, Penttila A, Kovanen PT (1994) Accumulation of activated mast cells in the shoulder region of human coronary atheroma, the predilection site of atheromatous rupture. Circulation 90: 1669-1678.

39. Choy JC, McDonald PC, Suarez AC, Hung VH, Wilson JE, McManus BM et al. (2003) Granzyme $B$ in atherosclerosis and transplant vascular disease: association with cell death and atherosclerotic disease severity. Mod Pathol 16: 460-470.

40. Lu LF, Lind EF, Gondek DC, Bennett KA, Gleeson MW, Pino-Lagos K et al. (2006) Mast cells are essential intermediaries in regulatory T-cell tolerance. Nature 442: 997-1002.

41. Kummer JA, Tak PP, Brinkman BM, van Tilborg AA, Kamp AM, Verweij CL et al. (1994) Expression of granzymes $A$ and $B$ in synovial tissue from patients with rheumatoid arthritis and osteoarthritis. Clin Immunol Immunopathol 73: 88-95.

42. Kiener HP, Baghestanian M, Dominkus M, Walchshofer S, Ghannadan M, Willheim M et al. (1998) Expression of the C5a receptor (CD88) on synovial mast cells in patients with rheumatoid arthritis. Arthritis Rheum 41: 233-245.

43. Lee DM, Friend DS, Gurish MF, Benoist C, Mathis D, Brenner MB (2002) Mast cells: a cellular link between autoantibodies and inflammatory arthritis. Science 297: 1689-1692.

44. Johnston B, Burns AR, Kubes P (1998) A role for mast cells in the development of adjuvant-induced vasculitis and arthritis. Am J Pathol 152: 555-563.

45. Nishizumi H, Yamamoto $T$ (1997) Impaired tyrosine phosphorylation and Ca2+ mobilization, but not degranulation, in lyn-deficient bone marrow-derived mast cells. J Immunol 158: 2350-2355.

46. Bhakdi S, Bayley H, Valeva A, Walev I, Walker B, Kehoe M et al. (1996) Staphylococcal alpha-toxin, streptolysin-O, and Escherichia coli hemolysin: prototypes of pore-forming bacterial cytolysins. Arch Microbiol 165: 73-79.

47. Pardo J, Balkow S, Anel A, Simon MM (2002) Granzymes are essential for natural killer cell-mediated and perf-facilitated tumor control. Eur J Immunol 32: 2881-2887.

48. Pardo J, Perez-Galan P, Gamen S, Marzo I, Monleon I, Kaspar AA et al. (2001) A role of the mitochondrial apoptosis-inducing factor in granulysin-induced apoptosis. $J$ Immunol 167: 1222-1229.

49. Ebnet K, Suzuki A, Horikoshi Y, Hirose T, Meyer Zu Brickwedde MK, Ohno S et al. (2001) The cell polarity protein ASIP/PAR-3 directly associates with junctional adhesion molecule (JAM). EMBO J 20: 3738-3748.

50. Strik MCM, de Koning PJA, Kleijmeer MJ, Bladergroen BA, Wolbink AM, Griffith JM et al. Human mast cells produce and release the cytotoxic lymphocyte-associated protease gzanzyme B upon activation. Mol Immunol 2007; 44: 3462-3472.

\section{Supplementary Information accompanies the paper on Cell Death and Differentiation website (http://www.nature.com/cdd)}

